\title{
COMM151: A PROJECT-BASED COURSE TO ENHANCE ENGINEERING STUDENTS' COMMUNICATION SKILLS
}

\author{
Tanju Deveci ${ }^{1}$, Roger Nunn ${ }^{2}$ \\ ${ }^{1}$ Khalifa University of Science and Technology, Abu Dhabi, the United Arab Emirates \\ tanjudeveci@yahoo.com \\ ${ }^{2}$ American University of Sharjah, Sharjah, the United Arab Emirates \\ rogercnunn@yahoo.co.uk
}

\begin{abstract}
Engineering is a discipline that requires its practitioners to learn and use a variety of soft-skills, which include academic and non-academic written and spoken communication, interand intrapersonal communication skills, critical thinking ability, an ability to work in teams and an ability to analyze, interpret and synthesize interdisciplinary information from a variety of sources. However, students who pursue their engineering education in English as their second language can face formidable challenges acquiring these skills. It is our observation that such students are often only given assistance through English courses designed to improve their individual linguistic abilities. We believe that although this approach may help in the short term, it may not sufficiently cater for students' overall needs and well-being in the long term. With this in mind, this paper describes our attempt to reduce this problem in our local context of the Petroleum Institute (PI) through a long term innovation effort.

A project-based approach has been adopted to provide students with an opportunity to enhance their language skills through meaningful learning experiences that also develop professional, personal and academic skills. This approach has also allowed the university to meet ABET criteria related to communication needs of engineering students. In this paper, we give a detailed rationale for our belief that a holistic approach to developing abilities required by engineering and other students is a better option. This is followed by a description of the different components of our current curriculum that has been developed over 12 years. We describe particular activities, and discuss their merits. We also present students' perceptions about the impact of their project-based learning experience on their language and skills development. We also outline the way the course is designed to be adaptable for unpredictable future needs in a fast developing professional and academic environment.
\end{abstract}

Key words: project-based learning, active learning, engineering education, holistic approach

\section{INTRODUCTION}

Given the critical role of advanced technology in our lives today, engineering with its variety of sub-disciplines seems to have become one of the most attractive career choices available. More and more young people are opting for majors in engineering. In the European Union, for instance, engineering, manufacturing, and construction-related studies attracted $15.7 \%$ of all tertiary education students in 2013 (Eurostat, n.d.). Elsewhere, an increase of up to 29\% was seen in bachelor degrees in engineering fields in the 2013-2014 
academic year (U.S. Department of Education, 2016). A 2015 report issued by the Dubai Statistics Center, on the other hand, shows that engineering students accounted for only 9.3\% of the total number of students pursuing tertiary education in 2014.

The extensive use of English in information sources has motivated universities around the globe to use English as the medium of instruction in their engineering faculties. Engineers in the field are required to 'use' English extensively to communicate with colleagues from other cultures, and to keep up with emerging trends (Renukadevi, 2013). However, universities are faced with a challenge when trying to address the needs of students with limited second language ability. To alleviate this problem, universities often place newly-admitted students in preparatory English programs that typically last a year. However, a year of language training is frequently inadequate to prepare students for effective engagement with content matter in their departments. To further address the problem, students are often required to take freshman English courses to improve their language skills. These courses often focus on technical English requiring students to read and write technical documents displaying individual linguistic abilities. Although we acknowledge the contribution of this approach to students' technical communication ability, we believe that it likely falls short in preparing engineering students for the kinds of academic and nonacademic communication and the critical thinking skills they will need to exhibit as academics or practicing engineers in the future. In the context of the Petroleum Institute, we aimed to reduce this problem through a long-term curriculum innovation: carefully planned instruction based on the holistic and constructivist principles of problem-based learning.

\section{IMPETUS FOR THE INNOVATION}

In addition to technical/hard skills, engineers also need to acquire and exhibit soft skills. Although soft-skills are difficult to define and measure, they include team-building, problemsolving, analytical thinking, self-awareness, listening, and time-management (Bhatnagar \& Bhatnagar, 2012). "Engineers' personality traits, psychological profiles, value systems, and deep-rooted beliefs" (Chang, 2010, p. 144) play a role in their use of soft skills and their success in a company. Bhatnagar and Bhatnagar (2012) note that "in engineering, ... communication skills are often considered more important than high-level mathematics, group work skills are more important than academic individuality, and a commitment to lifelong learning and continuing professional development more important than a theoretical contribution to research-focused projects and development" (p. 5).

Several engineering accreditation boards have also endorsed soft-skills in their criteria. In their third criterion, the Accreditation Board for Engineering and Technology (ABET) (2014), for example, identifies the following soft-skills as essential soft-skills engineering students need to acquire: (d) an ability to function on multidisciplinary teams, (f) an understanding of professional and ethical responsibility, ( $\mathrm{g}$ ) an ability to communicate effectively, (h) the broad education necessary to understand the impact of engineering solutions in a global, economic, environmental, and societal context, (i) a recognition of the need for, and an ability to engage in, life-long learning, and (j) a knowledge of contemporary issues. Similarly, the Canadian Engineering Accreditation Board (CEAB) (2014) identifies attributes graduates need to have under a variety of headings such as individual and teamwork, communication skills, professionalism, ethics and equity, impact of engineering on society and the environment, and lifelong learning. Universities around the globe 
acknowledge the role foreign language skills in general, and English in particular, play in allowing students to develop these soft-skills. For instance, the Accreditation Board for Engineering Education in Korea (ABEEK) requires "engineering students to acquire English communication ability good enough to cooperate globally in their professional fields" (Kim, 2013, p. 45). Taken together, these approaches to engineering education highlight the significance of soft-skills for graduates to become or remain successful engineers. Although it would be wrong to separate soft-skills training from core technical content (Ozturk, Deveci, Gunister \& Simmons, 2015), we believe the English language training provided to engineering students could support students' development of these skills. However, we also believe that language training for engineering students should be contextualized in relation to the skills required in the various engineering disciplines. The Communication Department at the Petroleum Institute strives to do this through a course based on project-based learning, details of which we give below.

\section{THE CONTEXT}

In this section, we first give a general picture of our teaching context. Then we explain the rationale for a Communication course developed to enhance engineering students' soft-skills. In doing this, we will describe tasks and assignments designed to improve our students' English language skills through their engagement in a project-based learning (PBL) environment.

\subsection{The Petroleum Institute}

The Petroleum Institute (PI), founded in 2001, offers undergraduate and graduate studies in various engineering disciplines. Accredited by ABET, the PI pays special attention to teaching its students the required soft skills along with the technical knowledge and skills. As an English-medium university, the PI also aims to furnish students with the English language skills necessary for students to follow the latest engineering developments, write technical reports, present their work, and work on multi-cultural teams. Considering the multi-cultural composition of the UAE, the university has strived to nurture students' inter-cultural competences, as a key dimension of effective use of English as an international language in context. To this end, newly admitted students lacking the adequate language proficiency are placed in the Academic Bridge Program (ABP). Upon graduation from the ABP, students need to take two 4-credit Communication courses in the College of Arts and Sciences.

\subsection{Communication II}

Communication II (COMM151) focuses on the practical application of critical thinking, problem solving, and academic communication skills. As an important educational innovation, since the inception of our second communication course in 2005, we have built our academic literacy course round a semester-long team project. Students have undertaken this semester-long "real-world" project - either academic, educational, or technical. They do this in the context of PBL implementing a holistic approach to learning. Considering learning as a social activity within this holistic approach, students work in teams where individual holistic learners are expected to "achieve the highest aspect of awareness of knowledge and appreciate the value that it adds to [their lives]" (Patel, 2003, p. 3). This has represented a 
considerable innovation in our context, one that has been sustained over a considerable period of time through a process of continuous research and development.

The learning outcomes and performance indicators, which are based on PBL and guide the course content and design, can be seen in Table 1 below.

Table 1 COMM151 course learning outcomes and performance indicators

\begin{tabular}{|c|c|}
\hline Course Learning Outcomes & Performance Indicators \\
\hline $\begin{array}{l}\text { After completing this course, the } \\
\text { student will have: }\end{array}$ & Students will do this by; \\
\hline $\begin{array}{l}\text { CLO1. selected, developed and used a } \\
\text { combination of data gathering }\end{array}$ & $\begin{array}{l}1.1 \text { choosing and develop appropriate triangulated } \\
\text { instruments. }\end{array}$ \\
\hline instruments to undertake research. & $\begin{array}{l}1.2 \text { synthesizing data thematically from different } \\
\text { instruments. }\end{array}$ \\
\hline $\begin{array}{l}\text { CLO2. participated effectively and } \\
\text { professionally in a team. }\end{array}$ & $\begin{array}{l}2.1 \text { making useful and effective contributions to } \\
\text { processes and products. } \\
2.2 \text { collaborating and cooperating. }\end{array}$ \\
\hline $\begin{array}{l}\text { CLO3. demonstrated effective and } \\
\text { professional communication. }\end{array}$ & $\begin{array}{l}\text { 3.1 combining reading and writing skills effectively. } \\
\text { 3.2 giving an effective, interactive presentation. } \\
3.3 \text { extracting detailed information from dense scientific } \\
\text { academic texts and visuals, and applying critical } \\
\text { thinking to the information in texts. }\end{array}$ \\
\hline $\begin{array}{l}\text { CLO4. engaged in independent study } \\
\text { and the development of life-long } \\
\text { learning skills. }\end{array}$ & $\begin{array}{l}\text { 4.1 locating and organizing topic-relevant sources of } \\
\text { information about a specified topic from the } \\
\text { library and/or on the World Wide Web. } \\
\text { 4.2 demonstrating reflective and critical thinking skills. }\end{array}$ \\
\hline
\end{tabular}

As seen in Table 1, COMM151 is indeed a skills-based course with a holistic approach. By 'holistic', we mean that a broad range of skills, aptitudes and knowledge need to work in combination to accomplish a real world task successfully. The learning outcomes do not make explicit reference to the English language per se. However, language elements and skills are taught in combination to achieve the communication aims determined by the type of projects students are engaged in. In this way, they can better see the interdependence of language components and skills. The holistic approach provided by PBL supports students' development of English language skills by engaging them in extensive listening, reading, debate, observation and Internet searching (Qiang \& Wolff, 2009). Therefore, the holistic nature of PBL in COMM151 is based on the notion of "learning by doing ... increases student motivation while improving students' problem-solving and higher-order thinking skills" (Boss \& Krauss, 2014, p. 16). As such, it adheres to the principles of a constructivist approach suggesting that learners construct new ideas and concepts using their present and previous experiences (Karlin \& Vianni, 2001). Learning is student-centered, that is, arranged around purposeful supported but independent group-dialogue allowing learners to raise their awareness of metacognition and to change their understanding (Richardson, 2003).

The nature of PBL in COMM151 shifts the instructor's role to a supporting role assisting students in framing meaningful questions, planning meaningful tasks, and assessing their own development (David, 2008) as well as their team-members'. For success in these and similar situations, students need to be able to express themselves efficiently, resolve conflicts, and consult experts to make informed decisions, all of which requires effective use of language 
and critical thinking skills (Nunn, Brandt \& Deveci, 2016). It is only natural that performing these tasks in a foreign language poses an extra challenge to students. To minimize this problem, the instructor becomes "an ally in the learners' process of acquiring a foreign language [and] facilitates, supports, animates, guides, asks questions, offers variety and choice, observes, encourages awareness and reflection" (Thienen \& Rosangela, 2009, p. 16). Such an approach, according to Patel (2003), allows the instructor to help students develop as critical, confident, and independent learners who possess the ability to take action in real situations. To support our students' acquisition of these attributes, we take an opportunistic approach, but we do focus on form in English language use whenever required for students to perform successfully in situations dictated by their project work. This is especially important when responding to drafts of written reports, where clarity and accuracy are required.

\subsection{Learning experiences and assignments}

To facilitate students' engagement in PBL while promoting meaningful use of the target language, a variety of learning experiences are planned. One of these is the overarching task of conducting a research project. Having completed a preliminary course, COMM101, students are expected to be familiar with the fundamentals of designing and conducting a study on a topic relevant to their lives as freshman students. COMM151 aims to build on the research skills students acquired in COMM101. However, this time they are encouraged to choose technical topics of general interest such as recycling, solar-energy, or mobile technologies. In this way, they gain exposure to more technical and scientific language. The intrinsic motivation created by their own choice of topics likely provides them with greater engagement in the target language.

\subsubsection{Team meetings}

The fact that they conduct the project in teams requires them to use English to express preferences, justify choices, and negotiate decisions. This often takes place during official team meetings, for which they are required to keep minutes. This experience further engages them in formal language use in written and spoken formats. Formal training provided by the classroom teacher prepares them for different roles during team meetings. As the minutes are relatively short, a very high level of accuracy is required, and each sentence is scrutinized by instructors. In this way, they are helped to write concisely, clearly, and accurately. They also learn to include only what is relevant and important. Taken together, their experience holding formal team meetings and documenting what is covered in the meeting engages them in meaningful use of English in real life situations.

\subsubsection{Individual literature review}

Another task COMM151 students are assigned is an 'individual team literature review'. Each team member selects two texts based on their usefulness and relevance to the team project. Students are normally asked to select academic texts from authoritative sources. However, they might also choose texts that do not report research directly from sources that provide vital factual or scientific information on the topic. This task is intended to help them to understand important variables, concepts, and theories that are relevant to their topic, to familiarize themselves with available research and make comparisons, and to evaluate what has been done by other researchers. This may help them work out what has not yet been done, 
give them ideas about the most appropriate and original contributions their teams can make, select an appropriate research method for their topic, and summarize important background information. In drafting their individual literature review, they normally combine different approaches: they normally need to paraphrase and identify useful direct citations.

\subsubsection{Proposal}

The individual literature review is followed by 'a proposal', which includes several subsections. In the introduction, it explains the importance of the chosen topic briefly justifying their rationale for their choice of topic. This is followed by a background section where the teams demonstrate their knowledge of the issues surrounding the research. In this section, they use relevant sections from their individual literature reviews, practicing the skill of synthesis. The proposal also requires a clear statement of purpose, focus and scope, as well as research question(s). On the other hand, in the method section students are required to provide a description of the kind of data needed to answer the research question(s), and how exactly data will be collected. When drafting their schedule, teams are asked to break down their project into smaller parts. For example, "doing a survey" involves defining their purpose, writing the survey questions, pre-testing the survey, and gathering the data. They need to estimate how long each of these tasks will take before assigning them equally among team members. They also need to set deadlines and have contingency plans. They are taught to use a Gantt chart to show the details of their research. They are also expected to estimate their budget, considering both how much money they would need in a real life situation, and what they would need to spend it on. Teams can also be required to present their proposals to their instructors and peers to justify their choices and to engage in dialogue to improve their research further before they start collecting data. After their instructor's approval, teams develop their data-gathering instruments.

\subsubsection{Progress report meeting}

Through classroom instruction and consultation sessions during and outside class time, instructors guide teams, facilitating their experiential learning experiences. However, at a certain point -usually during the data collection and analysis stage-, students are also required to hold a 'progress report meeting' with their instructors. This meeting normally takes the form of a structured discussion on progress in phase one of the project, but it can also take the form of a presentation. In a progress discussion/presentation, students are expected to exercise critical thinking about the process and quality of their research. The discussion might be built around a data retrieval system and a time management system such as a Gantt chart. One important purpose of a progress report is to make sure that the team is on track to complete the project as successfully as possible by the deadlines. Self-awareness is important; therefore, students are expected to identify and show awareness of their own problems. They are also expected to identify and explain significant achievements already completed. Other general topics for discussion are the team's ability to meet deadlines, reasons for any changes in the schedule or modifications in the original plan, and things that have been learned from problems faced at earlier stages of the project. A team should also be able to exploit the discussion to generate constructive ideas to improve their project and show readiness and ability to adapt their plan in response to any reasonable criticisms that arise from the discussion. They should also be able to defend their project when they do not agree by using their researched evidence, their knowledge of their research topic, or their findings up to that 
point. The overall experience of progress report meetings provides students with opportunities for exercising both intrapersonal and interpersonal communication skills. The former takes the form of self-talk, reflective thinking, emotional intelligence, and response preparation, while the latter occurs when learners need to communicate with their team members and instructor (Deveci \& Nunn, 2017). For both, if not more for the latter, students need to be efficient users of English language.

\subsubsection{Research report}

Students are also required to write a final report comprised of an abstract, introduction, research questions, literature review, description of the focus and scope, methodology, results, discussion, recommendations, conclusions, references, and appendices. The final product should be professionally drafted with all the feedback received since the beginning of the project being considered. It should be presented and carefully proofread before submission.

In the results section of the report, students present all the relevant findings using visuals in the form of figures and tables. In the discussion section, on the other hand, they summarize their research aims, questions, and sub-questions, before answering the questions theme by theme in linked paragraphs based on their findings. In doing so, they are encouraged to refer back to the literature, explaining, for example, whether their findings confirm, contradict, or add to other researchers' findings and conclusions. The discussion section is followed by the recommendations section where they offer suggestions to relevant stakeholders based on their findings. Students justify and rank their recommendations in terms of feasibility and importance.

\subsubsection{Multi-media oral research presentation}

The final course activity is an oral presentation supported by a variety of media. It is performed in teams. All team members are expected to participate equally in both the preparation and the performance of the presentation. Teams are encouraged to use all their creative and persuasive abilities, but should also support their arguments with facts and evidence from two data-gathering instruments.

The presentation typically summarizes the findings from the full project and then narrows the focus. Presenters are advised to provide full background information on their topic, explain the importance and relevance of their choice of topic for an academic audience, and clearly define and explain their research focus, questions, and aims. The presentation might typically focus on a problem or issue identified in the first phase. It may not need new data, but will need to fill any gaps identified in the earlier stages, and might require further reading. Presenters should not only explain the choice of the problem or issue in a clear and focused manner and report their findings, but also make recommendations for feasible actions to be taken by any interested parties.

Presenters should also demonstrate an ability to deliver their spoken message persuasively in a creative, engaging, and intelligible manner; they are advised to rehearse so that each speaker coordinates well with the others and with the media being used. They should use appropriate verbal and non-verbal skills to communicate with the audience and should not be reading from a script, although they may have cue cards as a support. Some sections may be fully rehearsed and scripted, but presenters should also consider spontaneity and fluency throughout. Presenters are also required to engage with the audience at different stages of the presentation. Accurate language is needed throughout to present the researched message concisely and clearly. 


\subsubsection{Seminars and reflective writing tasks}

In order to familiarize students with communication theories and help them increase their communication skills, we organize seminars at regular intervals on topics such as effective listening, interpersonal communication, intrapersonal communication, and intercultural communication. Students are assigned texts that are accompanied with a variety of reading activities such as annotation, guided note taking, and critical comprehension questions. The general aim is to identify the most important concepts or ideas in the texts. This assists students in preparing themselves to discuss seminar topics in the class seminar. Seminars are student led and often revolve around discussions on students' interpretations of the seminar topics in relation to their own experiences. This supports a constructivist approach to learning by suggesting that they construct new ideas and concepts using their current and previous experiences (Karlin \& Vianni, 2001).

Instructors conduct input sessions on what a seminar is, and how it differs from a lecture. They also run the first seminar, on effective listening, to provide a model for the students, who are responsible for running the others. In this way, students assume active roles in preparing for the seminar and engaging their peers in meaningful learning activities. Seminar discussions are followed by reflective writing examination tasks requiring students to reflect on their own experiences in relation to the seminar topics. We believe the reflective writing experience is of particular importance for not only engineering students but also potentially for any professional or even academic discipline (Nunn \& Brandt, 2016). It helps them develop the habit of engaging in meaningful intrapersonal communication. At the same time, reflective writing involves analyzing, interpreting and evaluating the experience as a way to improve similar future experiences. In Deveci and Nunn (in press), we discuss that engineers whose main responsibility is to enhance people's lives need to be aware of their own and others' needs, feelings, and reactions to events taking place around them. The reflective writing tasks assigned to students often include topics related to intrapersonal skills such as the use of emotional intelligence when working with others, conflict resolution skills, and time management skills; these seem to be lacking in many university engineering courses (Watson, 2013). Through the reflective writing experience, our students are encouraged to use a variety of critical thinking skills, which in turn helps them become self-directed learners (Lewittes, 2009). Their reflection on subject-specific topics in relation to their own experiences facilitates the process of integrating different pieces of information, as well as comprehending concepts (Deveci \& Nunn, in press).

In our context, we also see reflective writing as a form of interpersonal communication insomuch as their written output is to be read by someone other than themselves, which in this case is their instructors or fellow students, obliging them to tailor their rhetoric to the needs of their audience. To this end, they need to use the target language in intelligent ways paying attention not only to grammar and mechanics but also to content and organization. The input sessions about effective reflective writing raise students' awareness of such features, and give them opportunities to practice them. Therefore, this whole experience improves students' softskills as well as their language competencies.

\subsection{Assessment}

Students' work is assessed using tailor-made rubrics divided into four categories. The rubrics are specially designed to both cater for the holistic fulfilment of the whole task and to 'zoom-in' on important more atomistic aspects of the task. (See Nunn \& Thurman, 
2010, for a detailed discussion). Task is the most holistic category of the 4-part rubric. It refers to broad externally determined factors such as the genre of writing, for example, a proposal and the minutes of a meeting. It also includes individual instructors' instructions and emphasis on features like the number of words and subtopics that must be addressed. On the other hand, organization is related to the macro-structure of student output and focuses on the coherence of the way the task is drafted or presented. In the case of written output, the development throughout the piece and the transitions between paragraphs are important. Content, which refers to information content within sections and paragraphs, is related to the quantity and relevance of information, the quality of supporting evidence, and the argumentation in support of the claims and statements made within sections and paragraphs of the piece. In the case of a literature review, for example, students are expected to explain each theme they identify with adequate information from a variety of sources. The last category is language, which refers to the detailed and specific choices made between and within sentences. It includes accuracy, clarity, style and concision of the sentences used. It also includes mechanics (i.e. punctuation and spelling), lexis (i.e. collocation, colligation, syntax), and formality.

The divisions outlined above do not necessarily mean that the sub-categories are to be seen as separate; there is in fact inevitable overlap between them. For instance, unclear language makes it difficult to understand content, and poor choices in language areas such as modality affect the quality of the content. Language choices contribute to the overall coherence of the text and all sub-categories contribute to the successful holistic fulfilment of the task.

It is also important not to see the rubrics simply as assessment tools. They also help teaching and especially learning processes when they are seen "as a means to help [instructors] guide students on their road to learning" (Frank, 2012, p. 32). That is, instructors who are clear about student expectations can plan their instruction in a way that allows students to achieve learning outcomes (Wolf \& Stevens, 2007). When students are well-aware of the components of the rubrics used to assess their performance, they can perform complex tasks more efficiently, trying to meet the expectations (Wolf \& Stevens, 2007).

\section{EVALUATION OF THE INNOVATION}

In this section, we evaluate the extent to which our holistic approach has been successful. To do this, we first report the results of studies we have conducted into different aspects of the course. This is followed by the results of course evaluations performed by the students, which we believe helps students reflect on their learning.

\subsection{Research on Communication courses at the PI}

Both individually and collectively, we -as the authors of this paper and the teaching faculty in the Communication Department- have investigated various aspects of our Communication courses in general and COMM151 in particular with a view towards developing students' academic literacy and soft-skills. This community of researchers is investigated and described in more detail in Wyatt and Nunn (2017). Brandt (2011), for example, investigated the impact of team formation processes on curriculum Craig and Bielenberg (2015) investigated the promotion of a culture of inquiry by foregrounding research skills in first and second year engineering students. Craig and Dalton (2014) researched the way our first-year students develop a holistic platform for a culture of inquiry. 
Hatakka (2008) examined teacher beliefs about our context-based, situated learning. Nunn (2012) examined classroom behavior, reflecting on 'method-in-use' within our local context and Nunn and Hassan (2015) and Nunn, Brandt and Deveci (2016) linked this to the teaching of critical reasoning using our classroom-recorded 'method-in-use' protocols.

The collaborative nature of our courses allows for research into interaction patterns and how they affect students' learning styles and strategies. With this in mind, some of our research focused on students' adaptation of social learning styles (Deveci, 2013). It appeared that students' engagement in constant teamwork played a significant role in increasing their scores for collaborative and participant learning styles. The students also decreased their average scores for dependent and competitive learning styles, allowing them to become more independent learners. The challenges they faced at the beginning of their studies in the Communication Department tapered off as they learned how to access sources and evaluate content more efficiently, the result of which was higher self-confidence.

COMM151 has also served as a venue for a student development initiative called 'The Freshman Year Experience" (FYE). This initiative aimed "to promote learner development through purposeful structured activities in order to provide students with the essential skills and knowledge required for a more fulfilling life at the university and beyond" (Deveci \& Ayish, 2017). Using students' reflective writing examination papers on two of the seminar topics (i.e. intrapersonal and interpersonal communication) as a data-collection method, we found that the reflective writing tasks helped students use their critical thinking skills and understand the FYE program's role in bringing about meaningful changes in the way they perceived themselves and others. In this way, the reflective writing tasks generated positive thoughts and emotions in students and helped them make sense of their new experiences in a holistic manner (Deveci \& Ayish, 2017).

Related to students' personal development in the FYE program was the enhancement of their emotional intelligence (EI), which was the topic of another recent study we conducted (Deveci \& Nunn, 2016). It was found that the increase in almost half of the students' IE scores at the end of COMM151 was at a statistically significant level. They increased their scores particularly in the subscales of managing others' emotions, perceptions of emotions, and utilization of emotions. When the factors contributing to increases in their EI scores were investigated, it appeared that the research project they undertook was the main factor. This required them to hold team meetings where they discussed issues related to their research. This gave them the opportunity to raise both their own and their teammates' thoughts and feelings about different issues and became more tolerant. Another commonly mentioned factor was the seminar topics, which increased students' knowledge and skills of various communication styles and therefore had positive effects on their EI. Related to this were their reflective writing exams, which were cited by $53 \%$ of the interviewees as a factor.

Further research focused on students' linguistic competencies. In one such study, we investigated the lexis used in the seminar texts and the students' use of different vocabulary items in reflective writing examinations based on those seminar texts. (Deveci, 2015). In this study, we found that the COMM151 seminar texts were adequate in terms of academic lexis; and certain lexical items in the academic word list also appeared in the students' lexicon. In another recent study related to lexis (Deveci, in press) we investigated collocations used in one of the seminar texts, and how students' exposure to these affected their production of collocations in their reflective writings. It was revealed that the 17.3 percent collocational coverage in the seminar text exposed students to a great variety of collocations. The use of academic words in their collocational forms was particularly 
important to note. When the students' use of collocations in their reflective writing papers was considered, a 7.69 percent-collocational coverage was detected. Taken together, the results of all these studies indicate at least some positive effect from students' engagement in the seminars through their readings and discussions on their academic language usage and some long term advantages in a holistic PBL learning platform.

\subsection{Course evaluation results}

The effectiveness of a course can be assessed by considering the quality of students' selfstudy assignments, which is partially reflected in student grades at the end of the course which are closely relatable to our holistic rubrics. However, it is also important to identify how students feel about and evaluate their own progress throughout the course. When used "in a more intuitive and holistic way ... considering all of the learning that took place in various ways in a course" (Cranton, 2011, p. 3), self-evaluation can be particularly useful. It engages students in reflection on their learning experience by exercising critical thinking. As a result of conscious self-reflection, they can "focus more fully on the behaviors that will increase [their] competence through academic achievement" (Sullo, 2009, p. 120). This also allows instructors to identify student strengths and challenges, giving them insight into how to reinforce learning further and how to cater to student needs better by adjusting the course as needed. With these in mind, we studied how 534 COMM151 students over the last two academic years evaluated their own progress and certain aspects of the course. We first asked how they felt about their development in the four English language skills. The results can be seen in Table 2 below.

Table 2 Student perceptions on four skills

\begin{tabular}{lcccccccccc}
\hline & \multicolumn{2}{c}{ A lot } & \multicolumn{2}{c}{ Quite a lot } & \multicolumn{2}{c}{ A little } & \multicolumn{2}{c}{ Not at all } & \multicolumn{2}{c}{ Total } \\
\cline { 2 - 11 } & $\mathrm{f}$ & $\%$ & $\mathrm{f}$ & $\%$ & $\mathrm{f}$ & $\%$ & $\mathrm{f}$ & $\%$ & $\mathrm{f}$ & $\%$ \\
\hline $\begin{array}{l}\text { My presentation skills } \\
\text { have improved. }\end{array}$ & 201 & 38 & 233 & 44 & 90 & 17 & 10 & 2 & 534 & 100 \\
$\begin{array}{l}\text { My writing skills have } \\
\text { improved. }\end{array}$ & 152 & 28 & 264 & 49 & 104 & 19 & 14 & 3 & 534 & 100 \\
\hline $\begin{array}{l}\text { My listening skills } \\
\text { have improved. }\end{array}$ & 149 & 28 & 258 & 48 & 105 & 20 & 22 & 4 & 534 & 100 \\
$\begin{array}{l}\text { My reading skills have } \\
\text { improved. }\end{array}$ & 109 & 20 & 263 & 49 & 136 & 25 & 26 & 5 & 534 & 100 \\
\hline
\end{tabular}

As can be seen in Table 2, the majority of the students thought their presentation, writing, and listening skills had developed (quite) a lot (82\%, 77\%, and 76\% respectively). The number of student who thought their reading skills improved significantly was comparatively lower $(69 \%)$ although still on the positive side. It is also important to note the percentage of the students who felt their four skills either improved very little, or not at all. It is likely that these students were particularly strong; they may have needed greater challenges to improve their skills further. Considering the number of scholarship students who enter the university with a high GPA, this may be a predictable result.

Considering the holistic nature of COMM151 in addition to its aim to enhance students' receptive and productive skills in English, we also wanted to identify their thoughts 
on their improvements in teamwork, planning, reflection, and critical thinking skills. The results can be seen in Table 3 .

Table 3 Student perceptions on team, planning, reflection and critical thinking skills

\begin{tabular}{lcccccccccc}
\hline & \multicolumn{2}{c}{ A lot } & \multicolumn{2}{c}{ Quite a lot } & \multicolumn{2}{c}{ A little } & \multicolumn{2}{c}{ Not at all } & \multicolumn{2}{c}{ Total } \\
\cline { 2 - 12 } & $\mathrm{f}$ & $\%$ & $\mathrm{f}$ & $\%$ & $\mathrm{f}$ & $\%$ & $\mathrm{f}$ & $\%$ & $\mathrm{f}$ & $\%$ \\
\hline $\begin{array}{l}\text { My team skills have } \\
\text { improved. }\end{array}$ & 219 & 41 & 216 & 40 & 82 & 15 & 17 & 3 & 534 & 100 \\
\hline $\begin{array}{l}\text { My organization and planning } \\
\text { skills have improved. }\end{array}$ & 185 & 35 & 226 & 42 & 108 & 20 & 15 & 3 & 534 & 100 \\
$\begin{array}{l}\text { My reflection skills have } \\
\text { improved. }\end{array}$ & 148 & 28 & 274 & 51 & 104 & 19 & 8 & 1 & 534 & 100 \\
$\begin{array}{l}\text { My critical thinking skills } \\
\text { have improved. }\end{array}$ & 193 & 36 & 234 & 44 & 93 & 17 & 14 & 3 & 534 & 100 \\
\hline
\end{tabular}

Table 3 shows that students had an overall positive attitude about their improvement in the specified aspects of their learning experience. Eighty-one percent of the students observed a significant amount of development in their team skills. Similarly, many indicated that their critical thinking skills together with their reflection skills had improved significantly (80\% and $79 \%$, respectively). On the other hand, a slightly lower number of students (77\%) indicated that the improvement was either a lot or quite a lot. Although very few in number, those who were dissatisfied stated that they did not notice improvements in these areas.

The Communication Department is the only department at the PI that offers fully-fledged project-based courses. This encouraged us to question students' overall perception of COMM151 in comparison to other courses they took. Focusing on this, we asked them to compare their motivation and workload in our course to those in other courses, the results of which can be seen in Table 4.

Table 4 Student perception of motivation and workload

\begin{tabular}{lccccccccccccc}
\hline & \multicolumn{1}{c}{ A lot higher } & \multicolumn{3}{c}{$\begin{array}{c}\text { Somewhat } \\
\text { higher }\end{array}$} & \multicolumn{1}{c}{$\begin{array}{c}\text { About the } \\
\text { same }\end{array}$} & \multicolumn{2}{c}{$\begin{array}{c}\text { Not as } \\
\text { high }\end{array}$} & \multicolumn{2}{c}{$\begin{array}{c}\text { A lot } \\
\text { lower }\end{array}$} & Total \\
& \multicolumn{1}{c}{} & f & f & $\%$ & f & $\%$ & f & $\%$ & f & $\%$ & f & $\%$ \\
\hline $\begin{array}{l}\text { In comparison to other } \\
\text { courses, I have had to } \\
\text { work }\end{array}$ & 159 & 30 & 230 & 43 & 110 & 21 & 32 & 6 & 3 & 1 & 534 & 100 \\
\hline $\begin{array}{l}\text { In comparison to other } \\
\text { courses, my motivation } \\
\text { in COMM151 is }\end{array}$ & 116 & 22 & 226 & 42 & 133 & 25 & 44 & 8 & 15 & 3 & 534 & 100 \\
\hline
\end{tabular}

As is seen in Table 4, a total of 389 students (73\%) noted that the workload was higher in COMM151 than in the other courses they were taking at the time. This, however, did not have a significant effect on students' motivation. That is, $22 \%$ of the students' motivation was a lot higher, and $42 \%$ of the students' motivation was somewhat higher in comparison to other courses. Nonetheless, it is also important to consider the number of students whose motivation was less in COMM151 (11\%). 


\section{IMPLICATIONS}

We believe that our project-based course outlined above has several implications.

a) In terms of management, it is clear that the department has benefitted from institutional support in setting up a holistic project-based environment without which none of the above could be considered feasible. A four-hour per week, four credit course is not the norm in many institutions nor indeed in ours. Considerable out of class effort by students and faculty is also an important constraint that requires institutional support. It is difficult to imagine a long-term innovation of this type which started in 2005 enjoying such long-term stability and development without this type of institutional approval. We hope that our paper may help readers who would like to adopt a similar innovation to argue their case. We also believe that a course that stands out from the standard 3-credit composition course is likely to need regular investigation by the type of teacher-researcher community that we have been fortunate to be able to develop.

b) An advantage of a project-based course is that the holistic outcomes can either be kept private or can be highly visible. They are potentially available for public display and presentation. We have experimented with different formats, such as public presentations, min-conferences, poster-presentations, presentation by faculty with first-year students at local conferences for teachers. Students' full project reports have also been provided for public display at such events both in the form of presentations and posters. Students take centre stage at these events.

c) A holistic approach to education is part of a constructivist belief system that projects values of individual excellence in relation to the alleged benefits learning through interaction and collaboration. It aims to develop habits of learning that lay the foundations for lifelong learning.

d) Our innovation has benefitted from large-scale buy-in by faculty. It is clear that institutional innovations either fail or succeed primarily in the classroom even when significant learning may take place beyond the classroom. This faculty support has partly been promoted through careful recruitment in what was a start-up institution. A sympathy for constructivist learning was a prerequisite for interview selection in the department recruitment process.

e) When a long-term innovation does appear to be successful, this is accompanied by successful faculty retention which has been a feature of our innovation.

\section{CONCLUSION}

In this paper describing a long-term educational innovation, we have argued that teaching English language skills to engineering students pursuing their education in a foreign language cannot be confined to micro-level language components in isolation from each other. Similarly, we also argued that relationships must be established between the various soft-skills engineering student need to acquire. Students have to use English language skills in relation to these soft skills. However, it is also important that a holistic approach be adopted to put these skills in a real-world context. It is our belief that projectbased learning (PBL) is suitable for this. We described the overall nature of one of our PBL-based Communication courses indicating how it supports students' language skills through the use of the soft-skills they will need as future engineers. The research we conducted into various aspects of the course appears to provide evidence that the course has 
enjoyed both cognitive and affective benefits. Students' perceptions of the course also indicate that they are generally satisfied with the contribution of the course to the development of their language skills as well as other critical thinking and organizational skills. Their comparisons between our PBL-based course and other non-PBL-based courses at the university revealed that many were more motivated despite the greater workload required. However, it is also important to note the negative thoughts of some students despite their smaller numbers. These students' perceptions could be investigated further to identify the factors limiting their satisfaction. We suspect that these students may have a more exclusively individual orientation to learning caused by their previous learning experiences in the region often based on rote-learning. They might benefit from further guidance in the team-based learning and teamwork which engineering as a discipline often requires, but we may also benefit from understanding their perspective more deeply as we do not believe that a constructivist approach is in any way opposed to successful individual learning.

\section{REFERENCES}

Accreditation Board for Engineering and Technology. (2014). Criteria for accrediting engineering programs: 2015-2016 Accreditation Cycle. Baltimore, MD: ABET.

Bhatnagar, N., \& Bhatnagar, M. (2012). Effective communication and soft skills: Strategies for success. Delhi: Pearson.

Boss, S., \& Krauss, J. (2014). Reinventing project-based learning: Your field guide to real-world projects in the digital age ( $2^{\text {nd }}$ Edition.). Eugene, OR: International Society for Technology in Education.

Brandt, C. (2011). The impact of team formation processes on curriculum alignment in communication courses in an international context. Practice and Evidence of Scholarship of Teaching and Learning in Higher Education, 6(2), 110-134.

Brandt, C. (2012). The case for reflexivity in developing ESL students' academic communication skills. Scottish Journal of Arts, Social Sciences and Scientific Studies, l(1), 34-49.

Canadian Engineering Accreditation Board. (2014). Accreditation Criteria and Procedures, published by Engineers Canada, Retrieved from www.engineerscanada.ca/sites/default/ files/2014_accreditation_criteria_and_procedures_v06.pdf

Chang, C. M. (2010). Service systems management and engineering: Creating strategic differentiation and operational excellence. New Jersey: John Wiley and Sons Inc.

Craig, R., \& Bielenberg, B. (2015). Promoting a culture of inquiry: Foregrounding research skills in first and second year engineering students. QScience Proceedings (Engineering Leaders Conference 2014) 2015:14 http://dx.doi.org/10.5339/qproc.2015.elc2014.14

Craig, R., \& Dalton, D. (2014). Developing a platform for a culture of honest inquiry and the academic construction of knowledge in first-year students. International Journal of Educational Integrity, 10(1), 56-69.

Cranton, P. (2011). Working toward self-evaluation. In V. C. X. Wang (Ed.). Assessing and evaluating adult learning in career and technical education (pp. 1-10). Hershey PA: IGI Global and Zhejian University Press.

Dalton, D. F. (2008). The foreign language engineering writer - what makes a readable memo report? ASEE/IEEE Frontiers in Education Conference Proceedings, Saratoga Springs, New York. 
David, J. L. (2008). What research says about/project-based learning: Teaching students to think. Educational Leadership, 65(5), 80-82.

Deveci, T. (in press). Analysis of collocations in a book chapter and learners' corpus \& teaching implications. Journal of Language Education and Research.

Deveci, T., \& Ayish, N. (2017). Engineering students' well-being experiences: A freshman year experience program. Transformative Dialogues: Teaching \& Learning Journal, 9(3).

Deveci, T., \& Nunn, R. (2017). Intrapersonal communication as a lifelong learning skill in engineering education. Higher Education Journal, 7(1). doi:10.2399/yod.17.009

Deveci, T., \& Nunn, R. (2016). Development in freshman engineering students' emotional intelligence in project-based courses. The Asian ESP Journal Special Issue, 12(2), 54-92.

Deveci, T. (2015). Communication students' use of lexis in a writing examination. The Asian ESP Journal, 17(1), 39-63.

Deveci, T. (2013). Adaptation of social interaction learning styles by freshman engineering students in communication courses. Higher Education Journal, 3(3), 121-128.

Dubai Statistics Center (DSC). (2015). Number of Students Increased in Dubai Colleges and Universities in 2014. Retrieved from https://www.dsc.gov.ae/en-us/DSC-News/Pages/ Number-of-Students-.aspx

Eurostat (n.d.). Tertiary education statistics. Retrieved from http://ec.europa.eu/eurostat/ statisticsexplained/index.php/Tertiary_education_statistics.

Frank, J. (2012). The roles of assessment in language teaching. English Teaching Forum, $50(3), 32$.

Hatakka, M. (2008). Research and Engineering Students: Teacher beliefs about contextbased, situated learning. TESOL Arabia Conference Proceedings, 1-15.

Karlin, M., \& Viani, N. (2001). Project-based learning. Jackson Education Service District. Retrieved from http://www.jacksonesd.k12.or.us/it/ws/pbl/

Kim, H. H. (2013). Needs analysis for English for specific purpose course development for engineering students in Korea. International Journal of Multimedia and Ubiquitous Engineering, 8(6), 279-288.

Lewittes, H. (2009). A critical thinking rubric as the basis of assessment and curriculum. In C. S. Schreiner (Ed). Handbook of research on assessment technologies, methods, and applications in higher education (pp. 22-46). Hershey, PA: IGI Global.

Nunn, R. (2012). Reflecting on method-in-use within a local context. Contemporary Issues in Language and Humanities, 2(1), 1-18.

Nunn, R., \& Hassan, A. (2015). Investigating the teaching of critical reasoning using 'method-in-use' protocols: A trial lesson analysis. In V. Reddy \& S. Marathe (Eds.). Language Teaching Matters (pp. 85-102). Hyderabad: EMESCO Books.

Nunn, R., \& Thurman, J. (2010). The benefits and challenges of holistic in-house taskbased language learning and assessment. Asian EFL Journal, 12(4), 11-32.

Nunn, R., \&. Brandt. C. (2016) A Phenomenological approach to teaching reflective writing. English Scholarship Beyond Borders, 2(1), 130-151.

Nunn, R., Brandt, C., \& Deveci, T. (2016). Project-based learning as a holistic learning framework: integrating 10 principles of critical thinking. The Asian ESP Journal Special Issue, 12(2), 9-53.

Ozturk, F., Deveci, T., Gunister, E., \& Simmons, R. J. (2015). Innovative instructional strategies for teaching materials science in engineering. In H. L. Lim (Ed.) Handbook of research on recent developments in materials science and corrosion engineering education (pp. 100-117). PA: IGI Global. 
Patel, N. V. (2003). A holistic approach to learning and teaching interaction: Factors in the development of critical learners. The International Journal of Educational Management, 17(6/7), 272-284.

Qiang, N., \& Wolff, M. (2009). China EFL: What is holistic English? Humanising Language Teaching, 2. Retrieved from http://www.hltmag.co.uk/ apr09/mart03.htm

Renukadevi, D. (2013). Communicative English: Why it is essential to emerging engineers; the challenges and remedies. International Journal of Education and Information Studies, $3(2), 51-53$

Richardson, V. (2003). Constructivist pedagogy. Teachers College Record, 105(9), 16231640.

Sullo, B. (2009). The motivated student: Unlocking enthusiasm for learning. Virginia: ASCD.

Thienen, K. V., \& Rosangela, B. (2009). A touch of hola! A holistic approach to language learning. Brussel: Drukkerij Room.

U.S. Department of Education, National Center for Education Statistics. (2016). Digest of Education Statistics, 2015 (NCES 2016-014)

Watson, F. E. (2013). Self-perceptions of interpersonal, intrapersonal, and leadership skills among recent engineering graduates: A qualitative study (Doctoral dissertation). Colorado Springs: University of the Rockies.

Wolf, K., \& Stevens, E. (2007). The role of rubrics in advancing and assessing student learning. The Journal of Effective Teaching, 7(1), 3-14.

Wyatt, M., \& Nunn, R. (2017). Project-based learning on undergraduate communication courses at an engineering university in the Middle East: A teacher cognition perspective. Manuscript submitted for publication. 